\title{
Health Connected System
}

\author{
Dina Khattab \\ Faculty of Computing and Information Technology, \\ Information Technology Department, King \\ AbdulAziz University \\ P.O. Box, 10177, Riyadh , 11433, KSA
}

\author{
Nahla AlJojo \\ Faculty of Computing and Information Technology, \\ Information Systems Department, King AbdulAziz \\ University \\ P.O. Box , 132139, Jeddah , 21382, KSA
}

\begin{abstract}
Health Connected System (HCS) is a system connecting the governmental hospitals in Jeddah to one system; one database through a website to a portal giving access to patients' full medical history. This means that hospitals associated with the system have access to any updates or additions to the patient's file by any doctor in any governmental hospital that the patient visits. The doctors, laboratory technicians, radiologists and pharmaceutical staff are all allowed to see the part that belongs to their respective profession enabling them to be fully aware of the patient's health condition without breaching the patient's privacy. The goal of linking governmental hospitals is to provide a comprehensive medical history of a patient for the doctors and medical professionals working in the governmental hospitals; to create correct and complete diagnoses based on full awareness of the health status of the patient and the results of their analyses to cure the patient from diagnosed illnesses without any medical errors. The system states the hospitals the patient has visited, the treatments the patient has received as well as all the patient's test results; enabling all future medical professionals the patient will see to be fully aware of their condition.
\end{abstract}

\section{General Terms}

Networking and communications, Game and software engineering.

\section{Keywords}

medical history; patient; governmental hospitals; linked hospitals; complete medical record, electronic health record in Saudi Arabia

\section{INTRODUCTION}

There is an increasing need to find efficient ways to ensure appropriate patient information transfer between hospitals. The common system in the governmental hospitals in the Kingdom of Saudi Arabia when it comes to patients' medical histories is that a separate file is kept per patient at each of the hospitals that patient has visited. The information on each patient is not shared automatically among the hospitals and therefore patients have to copy their files and take them to other hospitals if they are asked to. This results in the issues where in the case of older patients; doctors sometimes find it difficult to know the exact details of the patient's case [1]

Patients' medical records are scattered between hospitals and healthcare centers and can't be shared between two or more different hospitals simultaneously. This can prevent physicians and specialists from being informed about the full medical condition of the patient which may result in a reduction of $g$ the quality of the provided care. Electronic linking will enhance this quality and enable patients to receive enhanced treatments [1].According to an Institute of Medicine (IOM) report, between 44,000 and 98,000 Americans die each year as a result of medical errors that could have been prevented. Beyond the cost in human lives as a result of such errors, the loss of credibility and integrity of some medical centers as well as hospitals is also damaging [2].

People tend to use internet increasingly in their lives; checking for internet connections periodically anywhere they may find themselves. Reports indicate that $60 \%$ of people in the US who own smartphones use it daily to access the internet. It enables them to follow up on their businesses periodically and catch up on any updates upon its ongoing synchronization [3]

The electronic linking of governmental hospitals will bring about the possibility of accessing patients' medical records at all governmental hospitals which will also allow the patient to have complete approved documentation of the medical reports to allow the effective following up of the patient at any one of the linked hospitals [4].

The e- linking among the government hospitals could lead to effective diagnosis by doctors, as they will have full access to patients' medical history, increase the organizational communication and enhance integration between hospitals by facilitating the sharing of information and updates on patients [5]

Electronic linking between organizations and in many fields is very useful and is needed to improve quality, save time and to catch-up on any informational update. The world around us is emphasizing the importance of the electronic linking by implementing this system in many fields. As shown below:

- Saudi Drug Control completed linking all its main branches electronically, in collaboration with the National Information Center, in order to speed-up procedures and by using this electronic linking, all information will be shared which will save time and help to improve the quality of the work allowing the ability to control and follow-up all procedures. [6]

- Using electronic links between banks is considered as the quickest and the easiest way to perform financial operations, which include eliminating the use of paper as well as saving the client time in transferring money when moving from one bank to another. [7]

- Arab Open University (AOU) has different branches in a number of different countries. In every branch, students record their information on SIS (student information system), so the student can study in another branch in another country 
without the need to register again. SIS has linked student information between countries. SIS contains the personal student information and academic records of students, such as years of study, courses they have studied, the remaining material, grades of courses as well as the student's GPA. Student can also go to another branch to write a final exam and return to the original branch if there is a need [8].

The purpose of this article is to clarify the importance of linking hospitals electronically and sharing patient medical history records, so it becomes available and accessible for all authorized users throughout the participating governmental hospitals, which saves time by reducing queries about medical history and medical condition updates. The system will also make it easier to diagnose the patient's condition therefore negating. Overall, the use of health information technology via HCS should lead to more efficient, safer, and higher-quality healthcare; highlighting the importance of the use of HCS system between government hospitals in the Kingdom.

\section{LITERATURE REVIEW}

This section explores previous work covering Health Connected Systems, therefore providing a clear understanding for the technology used in the related systems and Health Connected Systems (HCS). There are many previous works such as the following:

\subsection{Electronic Health Record (EHR)}

1. EHR were classified on the basis of the International Organization for Standardization (ISO) definition [9]. According to this definition, the EHR means a repository of patient data in digital form, stored and exchanged securely and accessible by multiple authorized users. It contains retrospective, concurrent and prospective information and its primary purpose is to support continuing, efficient and quality integrated health. [10]. Table 1 summarizes the benefits of each attribute of EHR.

2. The EHR is an interwoven system consisting of a digitized health record and information system. Data collected within the EHR in the UK consists of:

- Administrative and demographic information, such as name, age, date of birth, , address and telephone number and measurements such as height, weight, Body Mass Index (BMI), and blood pressure

- Clinical and diagnostic information

- Results of laboratory and radiological investigations information on prevention of disease and screening, such as immunizations, cervical screening, smoking status and alcohol intake

- $\quad$ prescriptions issued using the EHR system

- free text entered during consultations

- Image files of documents scanned after being received from external agencies such as hospitals and social services.
Table 1: Shows the benefits of each attribute in EHR

\begin{tabular}{|c|c|}
\hline Attribute & Benefits \\
\hline $\begin{array}{l}\text { Immediate and universal } \\
\text { access to the patient record }\end{array}$ & $\begin{array}{l}\text { Due to the fact that there } \\
\text { will be less time spent } \\
\text { accessing charts and writing } \\
\text { identical notes as well as } \\
\text { there being more accurate } \\
\text { information, both efficiency } \\
\text { and quality of data will be } \\
\text { improved }\end{array}$ \\
\hline $\begin{array}{l}\text { Easier and quicker access to } \\
\text { the patient's medical record }\end{array}$ & $\begin{array}{c}\text { More efficient point of care } \\
\text { assessment and } \\
\text { data abstraction }\end{array}$ \\
\hline $\begin{array}{l}\text { Due to the use of the } \\
\text { automated method of } \\
\text { recording notes, all patient } \\
\text { information will have a } \\
\text { higher rate of accuracy and } \\
\text { level of detail }\end{array}$ & $\begin{array}{l}\text { Less mistakes will be made } \\
\text { as the medical professionals } \\
\text { will have access to an } \\
\text { excellent level of data to } \\
\text { help them make their } \\
\text { diagnoses and prescriptions }\end{array}$ \\
\hline Secure record keeping & $\begin{array}{l}\text { Overall, patient fulfilment } \\
\text { will improve as there will } \\
\text { be fewer missing records } \\
\text { thus negating needless } \\
\text { waiting periods and wasted } \\
\text { scheduled meetings; an } \\
\text { improved patient service }\end{array}$ \\
\hline $\begin{array}{l}\text { Reduce paper work and } \\
\text { documentation error }\end{array}$ & $\begin{array}{l}\text { The electronic system will } \\
\text { reduce operational costs as } \\
\text { petty mistakes practices } \\
\text { such as repeated records } \\
\text { and unnecessary processing } \\
\text { times will all be a thing of } \\
\text { the past. }\end{array}$ \\
\hline \multicolumn{2}{|c|}{$\begin{array}{c}\text { Adapted from: Healthcare Information and Management } \\
\text { Systems Society (2007) }[13]\end{array}$} \\
\hline
\end{tabular}

With an added effect of causing patients to become more involved in the process of obtaining health care and intern enhancing their health, electronic health record keeping methods can aid patients by enabling them to track their medical test results and related updates. Subsequently, automated record keeping systems like the EHR can help with scrutinizing the service being received thus aiding the control of accuracy and transparency stipulated that patients will also be safer due to there being less medical mistakes due to access to up to date information and also help investigations into the causes of different diseases as well as the effects of prescribed medicines. [11]

The EHR system can be identified as a storage system that can be represented as a database containing all medical information of an individual among different systems. This information should be easily retrieved and shared to the authorized health care providers in a way to protect the patient's privacy. EHR is considered as an integrated system that provides a comprehensive medical record for different organizations and contains all the hospital's main and supplementary departments. [12] 
The EHR system functions can be summarized as the following according to the Institute of Medicine of the National Academies (2003):

- Health information and data

- Result management

- Order management

- Decision support

- Electronic communication and connectivity

- Patient support

- Administrative reporting

- Reporting and population health

There are several benefits of EHR systems, the availability of the patient record in any time and any place and the easy access can support informed decisions which improve the patient's health. Reliable and easy patient information access and catch up updates besides allows sharing between hospitals [14].

\subsubsection{EHR United Kingdom}

With the goal of reducing the dangers and improving the accuracy of patient care, England's NHS is instituting an initiative named the Summary Care Records (SCRs). With the view of backing crucial and trauma patient cases, the SCR will record a limited level of patient data for every patient in England who opts in to the idea. The information will be gathered from GP records and will enable fluidity of care. The database will contain specific information such as allergies and current medicines being taken. Both patient and doctor has required access to add to the stored information when necessary however other medical staff will need to request permission before viewing the patients SCR record as viewable information will be in levels depending on medical staff job title; non-clinical personnel will not be able to view clinical data apart from instances where it is needed for them to perform their duties. 27 million records had been created across England since 03/05/13.

The Emergency Care Summary (ECS) is Scotland's version of this initiative and the NHS in Wales is working on a similar system which has been named the Individual Health Record [15]

\subsubsection{EHR in Spain}

With implemented elements including patient identification, e-prescriptions, patient supervision modules as well as EHRs, a number of areas in Spain have their own version of the Electronic Health Record.

\subsubsection{EHR in Australia}

Recently, patients' medical records are shared via the internet through secured websites to maintain patient privacy; this allows patient information to be shared between different health care providers. The emergence of the EHR has facilitated the provision of an integrated patient record system which has helped doctors make more informed decisions thus reducing medical errors.

Data accuracy and completeness are very important factors that need to be available to the users of the system. The availability of these two factors will enhance and support the decision making process as well as the disease surveillance process. The provided data should be high quality because inappropriate data will badly affect the decision making process [16]. The Australian government considered the technological revolution as a key factor in contributing to savings of healthcare costs and subsequently raising the quality of healthcare services [17].

\subsection{Healthcare in Saudi Arabia}

The Kingdom of Saudi Arabia has spent billions of riyals to improve and develop the quality and the services available in the healthcare sector. The ministry of health provides around $60 \%$ of health care services while the remaining portion is divided between the private sector and other governmental bodies like the National Guard, the Ministry of Defense and Aviation, the ministry of interior and University hospitals. All this has led to the expansion of the health sector to cover all the parties in the Kingdom between private and governmental hospitals and medical centers. As a result no one provider has a complete medical record for one patient because the patient record has become scattered among these different healthcare providers. This scattering of the patient's health record may result in increasing additional costs in the treatment process. Patients could be asked to repeat some investigations (laboratory and radiology) and subsequently also repeat certain medications. The issue of opposing drugs may cause other health problems for the patient which could affect the safety of the patient.

Therefore there needs to be an electronic system to provide a complete medical history to all healthcare providers to support and enhance patient safety. Such sharing could be useful for all parties who are concerned about the patient's medical record [1].

- Benefits to Physicians:

- Physicians' diagnoses process decisions will be made after the physicians have been informed about the full case and the medical history of the patient.

- E-Health provides an effective system free from medical errors that could be from the result of poor handwriting or interpretation.

- Reduce time taken to search for investigation results and waiting time for ordering them.

- Facilitate doctor consultation on critical cases

- Benefits to Supplementary Departments (laboratory, radiology, pharmacy and nursing):

- Spend less time in entering data

- Reduce repeating some investigations and medicines

- Allow access to the necessary part of the patient's health record

- Benefits to Managers:

- E-health helps in moving patient information instantly around the health care providers and centres which reduce the cost of repeating medicines and investigations

- In case of a special investigation required and not provided in one organization, it can be found in another which enhances the quality of health care and the safety of the patient 
- Benefits to patients

- Prevent opposing medication errors which are dangerous

- Reduce time taken to follow-up investigation results

- The patient becomes aware about his medical case

\section{METHODOLOGY}

The overall methodology for the research consisted of:-

Stage1: Review literature and review previous works covering Health Connected Systems

\section{Stage 2: Questionnaire}

The questionnaire was distributed to two kinds of participants:

First questionnaire had been created and distributed to patients and it had been divided to three divisions. Firstly, they were to give their thoughts on the notion that there is a problem with patients not being able to collect their integrated medical record from one source. Next, they were to offer and discuss solutions to this issue and then finally offer their approval on the posed solution. The participants had been grouped according to their age, gender and educational level. The sample size according to the received replies was 132. The questionnaire was distributed between Jeddah and Riyadh:

In Jeddah the questionnaire was distributed to the staff of King Abdul-Aziz and its students, the National Guard Hospital and the Open University.

In Riyadh the questionnaire was distributed to the staff and patients of King Faisal Specialist Hospital and Research Centre, Al-Faisal University Students, patients and staff of the Kingdom Hospital and HP employees. (See section 4.1 for result)

The second questionnaire was created and distributed to doctors and physicians. The purpose of the first questionnaire was for patients to give their thoughts on there being a problem from patients' medical records being scattered among many hospitals and proving that the lake of information may lead to medical errors and loss of lives. The second part of the questionnaire was providing solutions and discussing it. The final part of the questionnaire was taking the approvals levels of the posed solutions.
Participants had been grouped according to years of experience. The sample size as per the received replies was 105. The questionnaire was distributed between Jeddah and Riyadh:

In Jeddah the questionnaire was distributed to doctors and physicians of National Guard Hospital and King Fahad Hospital

In Riyadh the questionnaire was distributed to doctors and physicians of King Faisal Specialist Hospital \& Research Centre and the Kingdom Hospital. (See section 4.2 for results).

\section{Stage 3: Interview}

An interview was conducted with Dr. Badawi, Consultant and Head of the Division of Surgical Oncology at the King Faisal Women's Specialist Hospital and Research Center in Riyadh. He was asked about the current system of medical record keeping in Saudi Arabia and he answered that the current system is limited and insufficient in providing all the medical information that could support the doctor's decisions due to the difficulties of collecting and gathering the patient medical record manually from many hospitals. He also expressed the difficulties faced in the diagnosis process due to the lack of patient's medical information and this lack could lead to medical errors as well as loss of lives. $\mathrm{He}$ agreed strongly with the idea of unifying patient medical record keeping via connecting hospitals together to connect the medical record due to the many savings that the system could provide to the pharmacy, radiology and laboratory departments in preventing repetitions and additional costs.

\section{RESULT}

Results from patients and doctors' questionnaires are explained as follows:

\subsection{Patients Questionnaire}

Patients had been asked and grouped according to their: Gender (59\% Female and $41 \%$ Male)

Age: Patients divided into three groups (38\% for ages $18-30$, $30 \%$ for ages $30-40$ and $32 \%$ for ages $>40$ ) Educational Level: patients grouped into four groups (1\% for less than high school, $7 \%$ for high school, $33 \%$ for bachelor degree and 55\% for higher education). The following Table 2 shows the results of the questionnaire of the patients.

Table 2: the patients' answers of the questionnaire

\begin{tabular}{|c|c|c|c|}
\hline \multirow[b]{2}{*}{ QUESTIONS } & \multicolumn{3}{|c|}{ ANSWERS } \\
\hline & YES & NO & SOMETIMES \\
\hline 1. Doctors asking for medical file & $58 \%$ & $25 \%$ & $17 \%$ \\
\hline $\begin{array}{l}\text { In your opinion are medical } \\
\text { errors related to the lack of } \\
\text { medical information for doctors? }\end{array}$ & $71 \%$ & $6 \%$ & $23 \%$ \\
\hline $\begin{array}{l}\text { 3. The ability to transfer your file } \\
\text { from one hospital to another (In } \\
\text { Case of answer is No continue }\end{array}$ & $52 \%$ & $21 \%$ & $27 \%$ \\
\hline
\end{tabular}




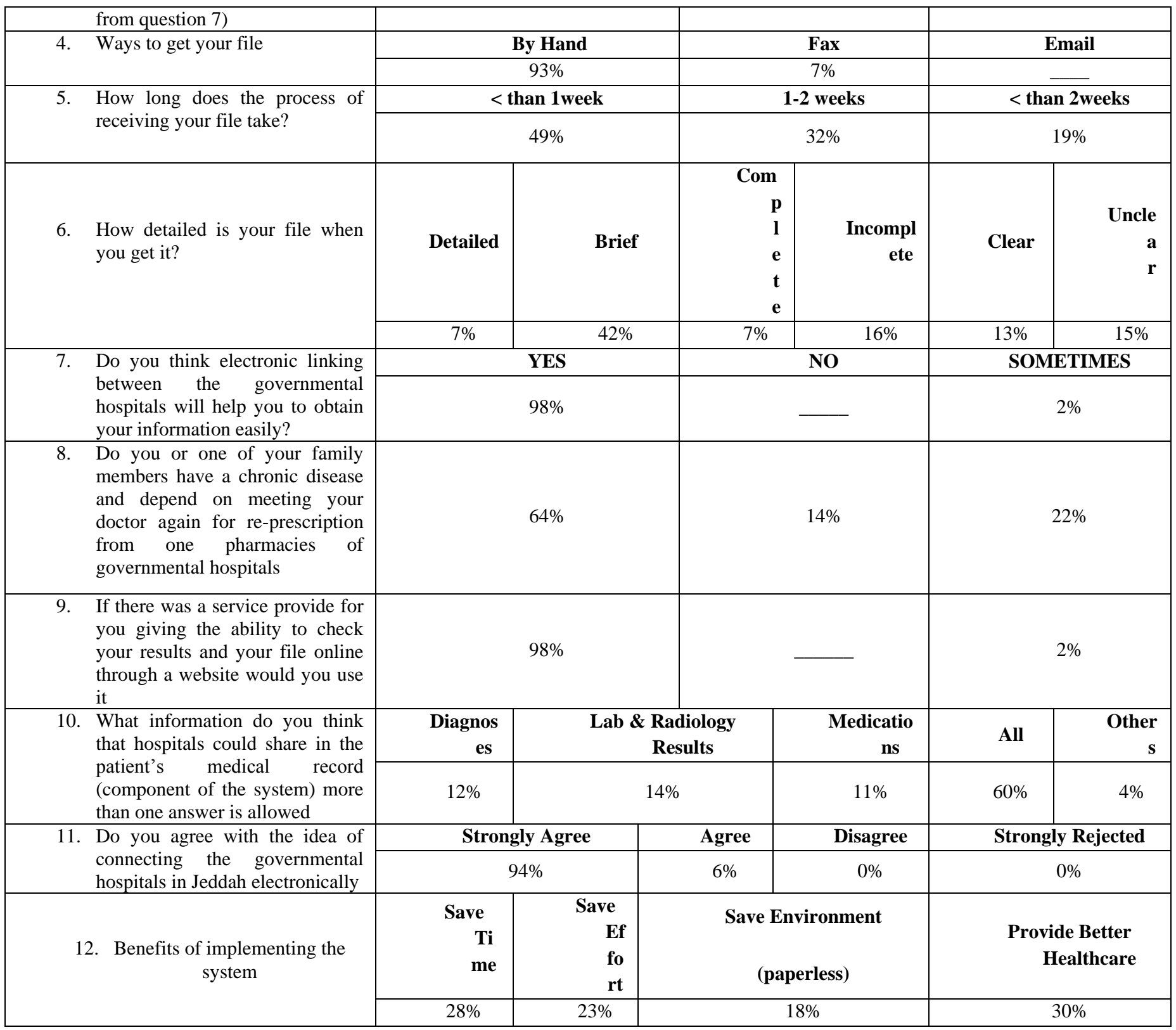

\subsection{Doctors and physicians Questionnaire}

Doctors and physicians are grouped according to their:

level of Education (38\% Consultant, $37 \%$ General, 9\% Professor and $16 \%$ Specialist)
Years of experience to find out how long they are accustomed to use the current system ( $30 \%$ less than 5 years, $45 \%$ 5-10 years and $25 \%$ more than 10 years). The table 3 shows doctors and physicians' answers of the questionnaire.

Table 1: The doctors and physicians answers

\begin{tabular}{|c|c|c|c|c|}
\hline \multirow{2}{*}{ Questions } & \multicolumn{4}{|c|}{ Answers } \\
\hline & Yes & No & Sometimes & Maybe \\
\hline $\begin{array}{l}\text { Do you face problems getting medical information } \\
\text { despite the information already being in the file }\end{array}$ & $62 \%$ & 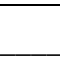 & $38 \%$ & \\
\hline $\begin{array}{l}\text { Is it important to know the results of laboratory } \\
\text { and radiology tests that the patient had recently }\end{array}$ & $94 \%$ & $3 \%$ & & $3 \%$ \\
\hline $\begin{array}{l}\text { Do you face problems in diagnoses because of } \\
\text { lack of medical information }\end{array}$ & $66 \%$ & $3 \%$ & & $31 \%$ \\
\hline Is there a need to implement the HCS between all & $100 \%$ & $0 \%$ & 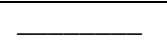 & $0 \%$ \\
\hline
\end{tabular}




\begin{tabular}{|c|c|c|c|c|c|}
\hline hospitals and to include all departments & & & & & \\
\hline $\begin{array}{l}\text { Do you think that the current system needs to be } \\
\text { improved }\end{array}$ & $100 \%$ & $0 \%$ & & \multicolumn{2}{|c|}{$0 \%$} \\
\hline \multirow[t]{2}{*}{ Having the full medical report will } & $\begin{array}{l}\text { Support } \\
\text { diagnoses }\end{array}$ & $\begin{array}{c}\text { Harm } \\
\text { patient's } \\
\text { privacy }\end{array}$ & \multicolumn{3}{|c|}{ Decrease medical errors } \\
\hline & $45 \%$ & $11 \%$ & \multicolumn{3}{|c|}{$44 \%$} \\
\hline \multirow[t]{2}{*}{$\begin{array}{l}\text { Benefits of implementing the system (more than } \\
\text { one choice is allowed) }\end{array}$} & Save Time & Save Effort & $\begin{array}{c}\text { Save } \\
\text { Environment } \\
\text { (paperless) }\end{array}$ & $\begin{array}{c}\text { Decrease } \\
\text { disturbing of } \\
\text { medications }\end{array}$ & $\begin{array}{c}\text { Provide } \\
\text { Better } \\
\text { Healthc } \\
\text { are }\end{array}$ \\
\hline & $21 \%$ & $23 \%$ & $23 \%$ & $16 \%$ & $17 \%$ \\
\hline \multirow{2}{*}{$\begin{array}{l}\text { System components (more than one choice is } \\
\text { allowed) }\end{array}$} & \multicolumn{2}{|c|}{$\begin{array}{l}\text { Laboratory \& radiology tests } \\
\text { results }\end{array}$} & Medications & Diagnoses & $\begin{array}{l}\text { Otherw } \\
\text { ise }\end{array}$ \\
\hline & \multicolumn{2}{|c|}{$32 \%$} & $31 \%$ & $31 \%$ & $6 \%$ \\
\hline \multirow[t]{2}{*}{ Do you agree with the system idea } & \multicolumn{2}{|c|}{ Strongly Agree } & Agree & Disagree & $\begin{array}{c}\text { Strongl } \\
\mathbf{y} \\
\text { Rejecte } \\
\mathbf{d}\end{array}$ \\
\hline & \multicolumn{2}{|c|}{$90 \%$} & $0 \%$ & $10 \%$ & $0 \%$ \\
\hline
\end{tabular}

\subsection{The Model of Health Connected System}

The Model of Health Connected System is designed based on the questionnaire, interview and previous studies. The model building is divided into two stages:

\section{Common Interface}

Common and shared interface between all the participating hospitals and patients, they will share the same designing in order of ease of use and implementation. This common interface represents the interface at the end users: see figure 1

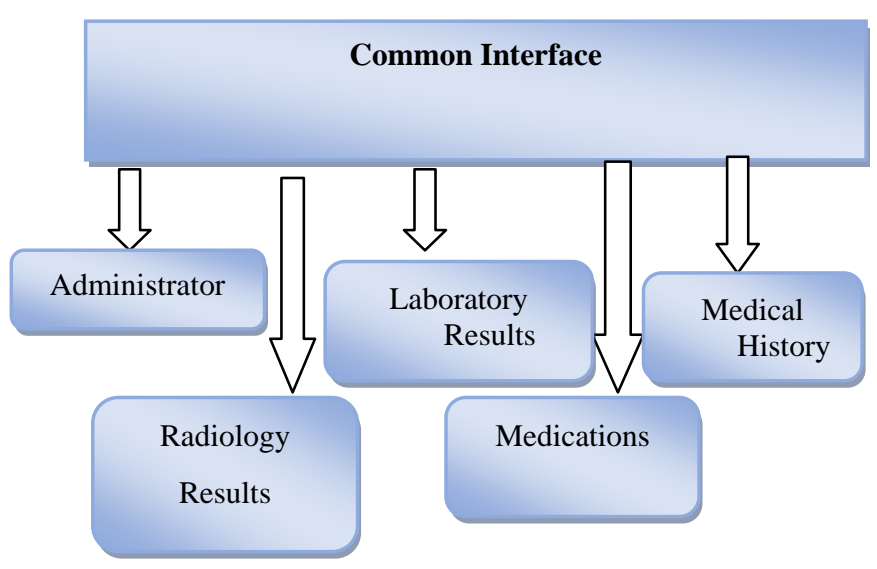

Figure 1: The Common Interface Components

\section{Data Integration}

This stage explains how the system exactly works upon datalevel. All the system components (laboratory and radiology results, administrator, medical history and any additional updates on the patient's record) reside in one huge database repository. Each component is recorded under the patient ID and calling these entire components required a special ID generated by the system and sent to the patient's email with a password to allow the patient login. The doctor's details require registration, just like the patient, following which a generated ID and password will be sent automatically to the email of the created user. Doctors logging in to any patient file require patient's ID.

In general the user's ID clarifies the type of user (patient, hospital staff) according to a special ordering in the ID numbers, as well as clarifying the hospital that the hospital staff come from.

All of this is just to provide a small model to prove the possibility of sharing the patient's medical record among different governmental hospitals and from different physicians. To connect and reach the data and to achieve the desired process of the data will be as the following figure2: 


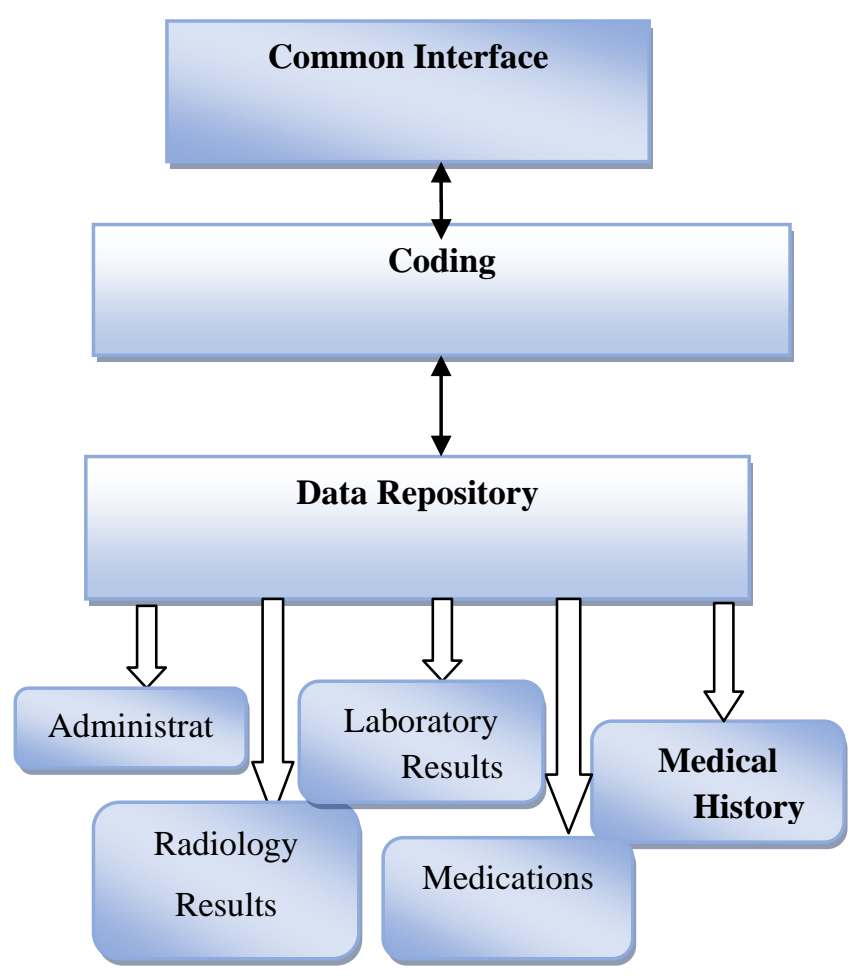

Figure 2: the Data Exchange Process

1. Implementation of Health Connected Systems

The effectiveness of the implementation of the system depends on the introduction of information in the system and provides a clear and easy to use source to the patient or doctor, where the system is always ready to provide the latest developments to have occurred to the patient .The system provides powers to the doctor and the patient in different ways. At any time, the patient can access the system and see the reports and analyses that concern him. Also the doctor can enter the system to know the patient's history and the additions to diagnoses, laboratory and radiology results and medications. The system is an integrated information system for patient medical record provided to doctors and patients. At the start of using the system each user has to login so he can use all the properties that are provided by the system.

The figures below show a simple and quick overview forthe most important pages for the users:

The system was implemented in two ways:

- A desktop system for the administrator to add patients and physicians. The administrator can use the adding property after sign in; the admin had been created by default and given an ID and password. The following figures show the adding process of patients and physicians to the system.

- A website created for physicians, patients and other users of the website consists of the basic threads of any website (home, about us, contact us pages, as well as an additional page called free consultation; its existence is optional)

\section{Administrator:}

The administrator will fill the required information to add a patient or physician and an automatic generating process of password and ID will be done, then the password and the ID will be sent to the inputted email as shown below: See figures 3 and 4

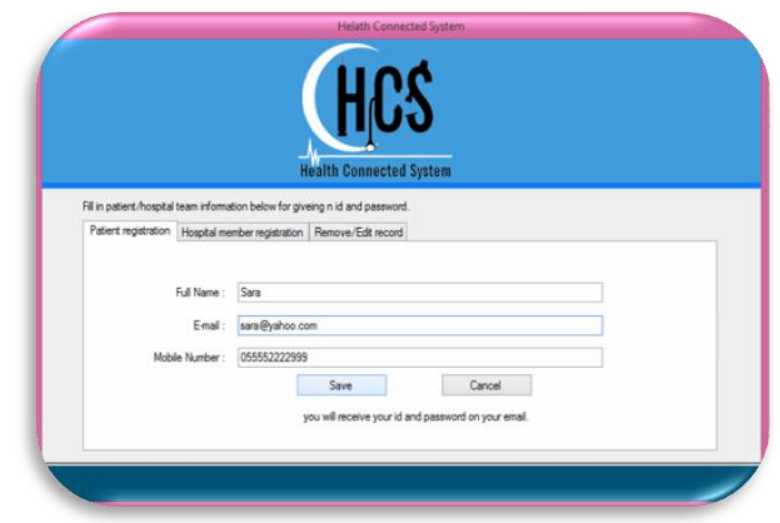

Figure 3: Adding patient to the system

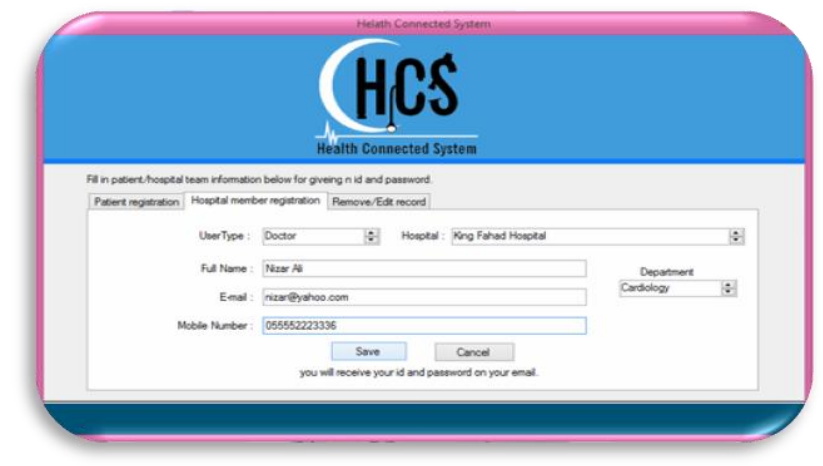

Figure 4: Adding physician to the system

Doctors

Doctors have to do the following first two steps to login to the patient medical record:

- Doctor must login

- Enter the ID of the patient to login to the patient record, then choose the desired property as shown in the navigation bar in the figures below.

The following figure shows the general information of the patient and enables the choice of department to check its diagnoses or choice of department (laboratory and radiology) to see the results. The interface also allows for the adding of new diagnosis as new case page. The radiology and laboratory results are marked with the consultation ID, date as well as time so the doctor can choose the desired date and the results will open immediately: see figures 5, 6 and 7 .

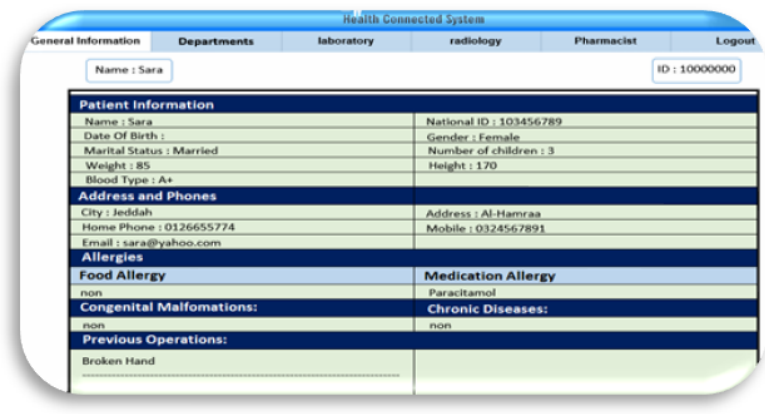

Figure 5: Shows the general information of the patient 


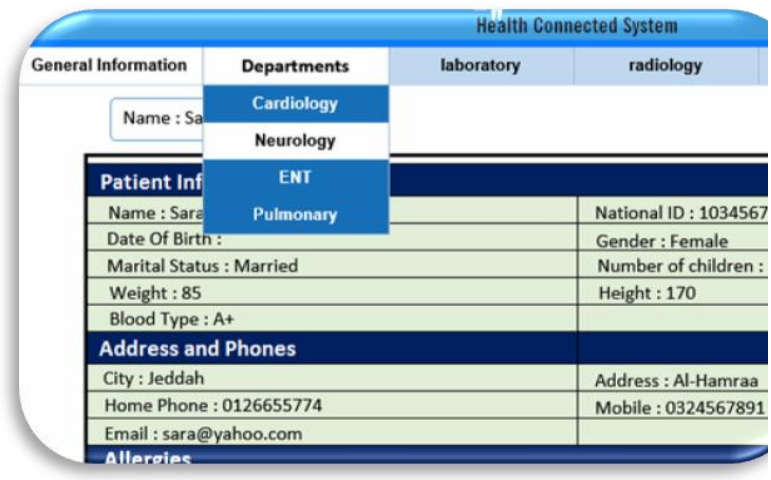

Figure 6: Choose the desired department

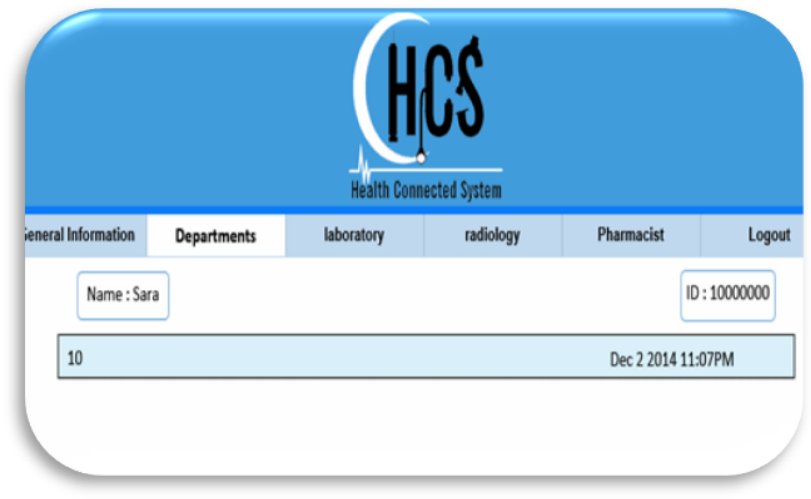

Figure 7: Shows the consultants according to the chose department

\section{Laboratorian:}

Firstly the laboratorian must login to see all the appending tests for all patients, as shown below: See Figure 8

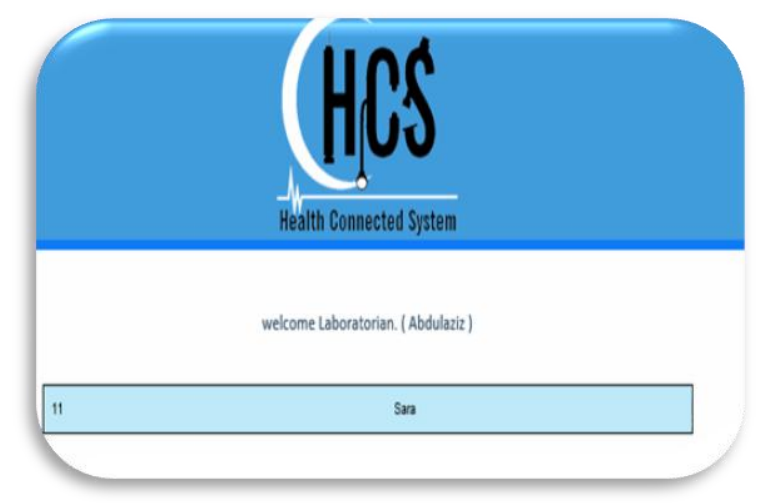

Figure 8: The appending tests of all patients

The figure 9 shows how to add results for each component of the required tests:

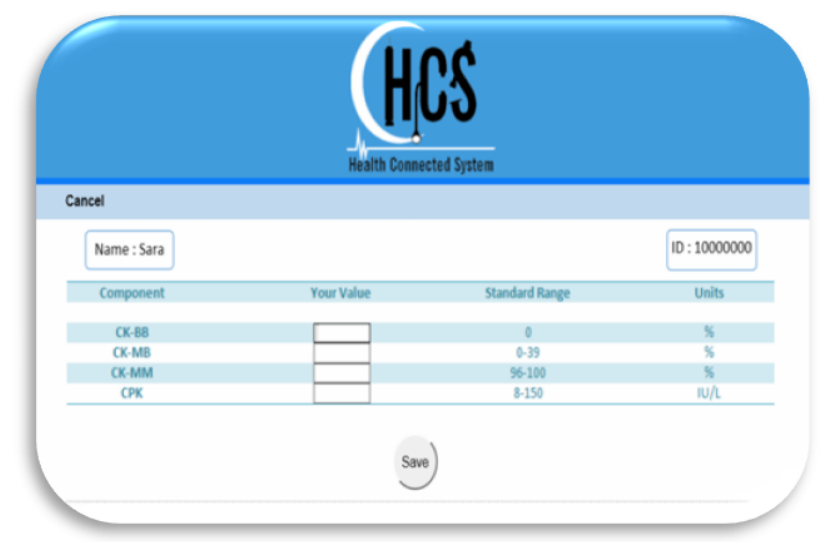

Figure 9: Adding the results of the components of the test

\section{Radiologist}

After logging in, the radiologist can view all the pending patients and choose one of them to fill the required information in for. They can then press save to be moved to the patient file immediately as shown below: see figures 10 \& 11

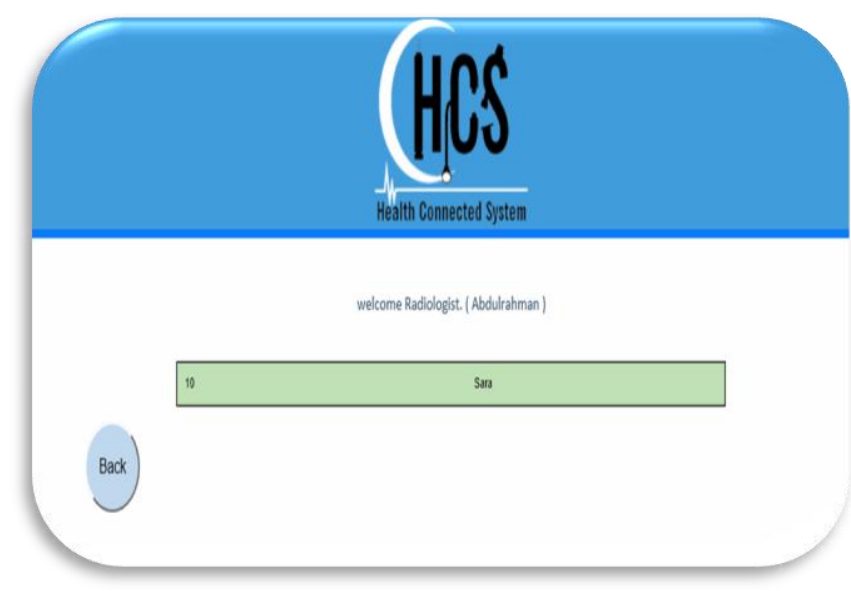

Figure 10: Viewing the pending patients

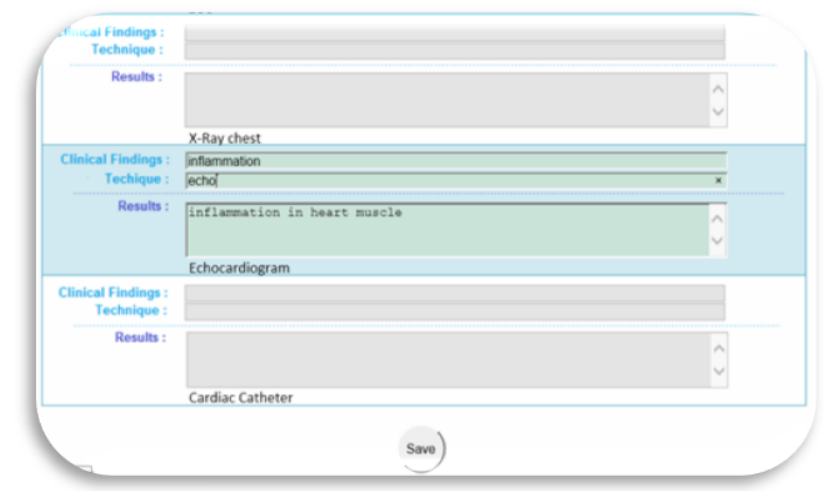

Figure 11: Add and save results

Pharmacist

The pharmacist had to login firstly then enter the ID of the patient to log into their file. In order to see the described medication, the pharmacist must click on the consultation button in the navigation bar as shown below. The pharmacist can also see the general information of the patient and can subsequently see all the previously described medications to avoid repetitions: see figures $12 \& 13$. 


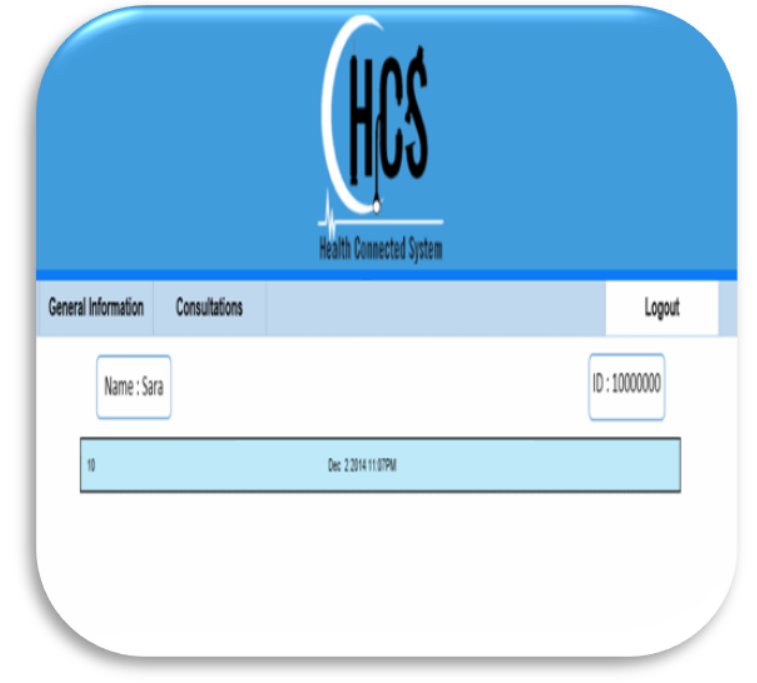

Figure 12: To view the described medications

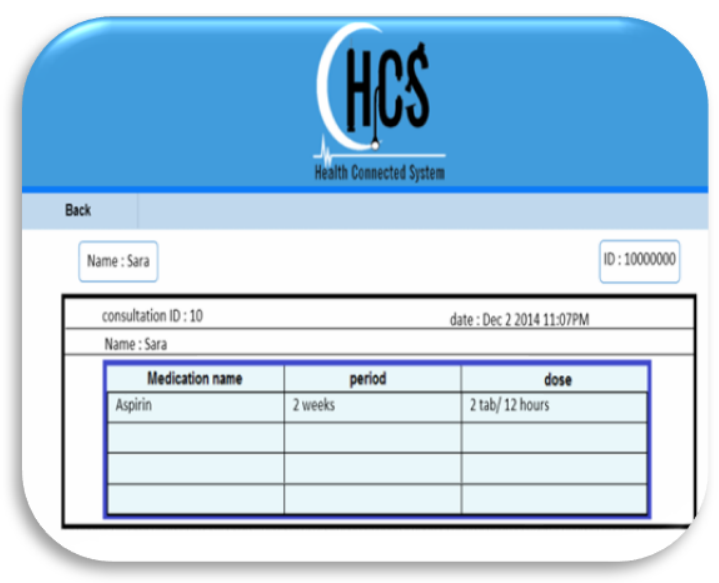

Figure 13: View the patient's prescription

\section{Patients}

Patients will login using the ID and password sent to their email. The patient will be able to view almost everything that their doctor can view. This is because they will have almost the same pages as the doctor.

\section{DISCUSSION}

\section{-Patients Questionnaire}

A large response had been received as pertaining to the patient questionnaire; about 132 replies. As general information was gathered about the sample who answered the questionnaire was $59 \%$ female and $41 \%$ male. Their ages were $38 \%$ for age $18-30,30 \%$ for ages $30-40$ and $32 \%$ for age that is greater than 40 . Their educational level was as $1 \%$ for less than high school, $7 \%$ for high school, 33\% bachelor degree and 59\% for higher education.

From the questionnaire and the gathered information, it is clear that people realise the importance of the historical record of the patient when moving between hospitals. For patient's that asked for their historical medical record, about 58\% faced this problem, $25 \%$ sometimes faced this problem and $17 \%$ claimed did not face this problem. This means that more than the half faced the scattered historical medical record problem. Many people faced the medical error issue either themselves or their relatives. When asked about the reason for the issue, $23 \%$ thought that the ignorance of medical history may lead to the medical errors situation while $71 \%$ thought that ignorance when it came to medical records was considered an important reason that lead to medical errors; only $6 \%$ thought that medical history won't affect the patient's health and medical errors.

Patients have been asked that in case they asked for their medical record is there any ability to transfer their record easily or their request may be refused by the hospital or the doctor. To this $52 \%$ faced a problem when they wanted to transfer their medical report from one hospital to another while $27 \%$ sometimes faced this problem; only $21 \%$ claimed they hadn't faced this problem yet.

All the people that have experienced the problem were asked how they received their file after the request was made. To this, 7\% was by fax and none by email; the majority of records were by hand which meant $93 \%$ faced this problem of the need to go to their hospitals and doctors more than once to finally get a copy from their medical record. Of this, $49 \%$ of the patients who get their files back took less than one week and $32 \%$ took between one to two weeks. $19 \%$ took more than two weeks to get their medical records which is a lot of time lost, considering the medical complications that could happen during that time. Patients were asked about the details in their record after receiving it and $15 \%$ received an unclear copy of their record that was written by hand. Only 13\% received clear information, with $16 \%$ receiving an incomplete medical record. Of the respondents, $7 \%$ received a complete medical record, $42 \%$ received a brief record without medication prescription, radiology and laboratory results and only $7 \%$ got a detailed medical record.

Around $64 \%$ of the patients needed to see their doctors again and again to get their medications or get their laboratory or radiology results, so $98 \%$ preferred to get their results and access their files online. Around 14\% didn't face the problem of having to see their doctor again, $22 \%$ may face this problem and $2 \%$ may prefer the online way to get their medical information. Also, $30 \%$ agreed that implementing the system will provide better healthcare for patients, $28 \%$ stipulated that it will save time, $23 \%$ chose that the implementation will save efforts and $18 \%$ considered the environmental issue because the system will transform the manual systems to electronic systems meaning a migration to a paperless system. Patients were asked if they desired components of the system to be shared between the hospitals (doctor's diagnoses 12\%, 14\% for laboratory and radiology results, $11 \%$ for sharing medication and prescriptions, $60 \%$ more than the half preferred hospitals to share all the previous information and $4 \%$ only answered 'other'). The respondents realised the importance and the meaning of sharing the medical record between hospitals to get a comprehensive historical medical record because $94 \%$ strongly agreed with implementing the system and 6\% agreed; there were no rejected opinions for implementing the system or for the idea itself.

\section{-Doctors and Physicians Questionnaire}

A large response had been received with regards to the patients' questionnaire; receiving about 105 replies. As general information gathered about the sample of doctors, $37 \%$ as consultants, 38 as general doctors, $9 \%$ professors and $16 \%$ as specialists. They were asked also about their years of experience to know how long they used the current system. The questionnaire clarified that $62 \%$ of the doctors faced problems of getting historical medical information and $38 \%$ 
sometimes faced this problem. Doctors were asked about benefits of getting full and complete medical records and $45 \%$ answered that this will create an informed decision process which will support diagnoses process. Of the respondents, $44 \%$ answered that it will decrease medical errors and only $11 \%$ thought that it will harm patients' privacy. Also, $94 \%$ answered that it's important to know the recent results of laboratory and radiology because that would affect their diagnoses, with $3 \%$ answering that it's not important and also $3 \%$ answering that maybe this would be important. Subsequently, $66 \%$ of doctors faced problems in diagnoses because of the lack of information while $31 \%$ thought maybe diagnoses might be affected. Around 3\% stated their diagnoses process will not be affected. About $100 \%$ agreed with the implementing of the idea on all departments and $100 \%$ confessed that the current system needs to be improves to enable medical records to be accessed everywhere and anywhere.

Doctors were asked about the system components and $31 \%$ agreed for doctors' diagnoses and $31 \%$ also for medications and prescriptions while $32 \%$ agreed for laboratory and radiology results and $6 \%$ only for otherwise.

For the benefits of the system $17 \%$ of doctors agreed that the system will provide better healthcare for the patients, $16 \%$ agreed it would decrease medication disturbances, $23 \%$ thought about the environment and chose that it will save the environment as it is a paperless system; $23 \%$ also chose that it will save efforts while $21 \%$ answered that the system will save time.

In conclusion, the majority (90\% doctors- $94 \%$ patients) were positive regarding the implementation and linking of hospitals for the sharing of medical records of patients to enable a comprehensive historical medical record whilst keeping the patients' privacy.

\section{CONCLUSION}

The Health Connected System is used to enhance and support the decision making process that relates to patients' health. HCS cares about providing a unified and better environment between patients and physicians around all the governmental hospitals to reach an accuracy and transparency with regards to patients' healthcare. HCS aimed to promote the healthcare sector in the community to accompany the challenges and the development around us. HCS aims to keep patients' rights and health away from any medical mistakes by providing a unified patient record among the governmental hospitals for physicians in such a way of exchanging patient medical information through exchanging data between systems using one data repository to keep all the information of the patients and all the information of the physicians of all governmental hospitals in Jeddah and to reduce the gap between hospitals as association and patients as customers. Hopefully by using HCS the community and healthcare sector will be served by making patients more aware about their health conditions as well as more honest physicians.

\section{ACKNOWLEDGMENTS}

We would like to thank Miss Nouf Rahimi for the support; patience and effort spent on us that is truly respected and appreciated.

\section{REFERENCES}

[1] Altuwajri, Majid, 2008. Electronic-Health in Saudi Arabia: Just around the corner. Saudi Medical Journal,

\section{9, 172-173.}

[2] Kohn, Linda, Corrigan, Janet M \& Donaldson, Molla S. 2000. To Err Is Human: Building a Safer Health System. 1st ed. Washington, D.C.: NATIONAL ACADEMY PRESS.

[3] The Importance of Responsive Design for Medical and Dental Website 2012 SNAP Healthcare Marketing. [ONLINE] Available http://healthcare.snapagency.com/the-importance-ofresponsive-design-for-medical-and-dental-websites/. [Accessed 01 April 2015].

[4] Abdullah, Al-Salem, 2012. 'Al-Rabiah: electronic link will provide follow-up of patients in all hospitals. Sabq, [Online]. Available at: http://wap.sabq.org/ryefde [Accessed 18 February 2015].

[5] CSIRO PUBLISHING - Australian Health Review. 2014. CSIRO PUBLISHING - Australian Health Review. [ONLINE] Available at http://www.publish.csiro.au/?paper=AH050012. [Accessed 19 February 2015].

[6] Saudi drug control complete electronic link between its branches, global information network about drug, 2014 Available from: $\langle\mathrm{http} / / /$ www.ginad.org/en/info?id=8347>. [Accessed 24 March 2015].

[7] Bank to Bank Electronic Links, NatWest, 2015. [ONLINE]Availableat:<http://personal.natwest.com/pers onal/lifemoments/travel/internationalpayments/receiving-money-from-abroad/bank-to-bankelectronic-links.html>. [Accessed 24 March 2015].

[8] Arab Open University. 2014. Arab Open University. [ONLINE] Available at: http://www.arabou.org.sa. [Accessed 24 March 2015].

[9] ISO/TR 20514:2005 - Health informatics -- Electronic health record -- Definition, scope and context. 2015. ISO/TR 20514:2005 - Health informatics -- Electronic health record -- Definition, scope and context. [ONLINE] Available at http://www.iso.org/iso/iso_catalogue/catalogue_tc/catalo gue_detail.htm?csnumber=39525. [Accessed 03 April 2015].

[10] Ha“ yrinen Kristiina, Saranto Kaija, Nykänen Prikko, 2008. Definition, structure, content, use and impacts of electronic. International journal of medical informatics, 77, 291-304.

[11] Josip Car, A. B. C. A. K. C. C. P., 2008. The Impact of eHealth on theQuality and Safety of Healthcare, London: Imperial College.

[12] Yaser, Alsahafi, 2012. Studies of EHR implementation and operation in different countries with particular reference to Saudi Arabia. Bachelor. Auckland, New Zealand: Massey University.

[13] Healthcare Information and Management Systems Society. www.himss.org/ASP/index.asp2007.

[14] AHRQ. Making health care safer: a critical analysis of patient safety practices [Publication]. Available at: http://biotech.law.Isu.edu/policy/ptsafety.pdf [Accessed 11 April 2015] 
[15] eHealth Stakeholder Group members, 2012. Available from: < https://ec.europa.eu/digitalagenda/en/news/ehealth-stakeholder-group-members $>$. [1 February 2012].

[16] Win \& Cooper, Khin \& Joan, 2004. Information age, Electronic health record and Australia healthcare. International Journal of the Computer, the Internet and Management, [Online]. 12, 14-21. Available at: http://www.google.com.eg/url?sa=t\&rct=j\&q=\&esrc=s\& source $=$ web $\& c d=1 \&$ ved $=0 \mathrm{CBwQFjAA} \&$ url $=\mathrm{http} \% 3 \mathrm{~A} \%$ 2F\%2Fwww.ijcim.th.org\%2Fpast_editions \%2F2004V12 N3\%2Fijcimv3n1_article2.pdf\&ei=Edc_VcviJ4qv7Aa-
ooDYBw\&usg=AFQjCNHUijKf5mfTm3hk4x0M-

TkRc_WoPA\&bvm=bv.91665533,d.ZGU [Accessed 15 April 2015].

[17] Brit, Winthereik, 2003. We Fill in Our Working Understanding": On Codes, Classifications and the Production of Accurate Data. Methods of Information in Medicine, [Online]. 0026-1270, 489-496. Available at: http://methods.schattauer.de/en/contents/archivepremium /issue/696/manuscript/321.html [Accessed 21 April 2015]. 